\title{
Customizing Mass Housing in Brazil: Introduction to an Integrated System
}

\author{
Alexander Lopes de Aquino Brasil ${ }^{1}$, Juarez Moara Santos Franco ${ }^{2}$ \\ ${ }^{I}$ Federal University of Rio de Janeiro - PROURB ${ }^{2}$ Federal Rural University of Rio \\ de Janeiro \\ 1,2 \{alex.abrasil02|juarez.moara.franco\}@gmail.com
}

\begin{abstract}
The current work presents an original parameterized wood frame system, a computational simulation of its structural performance and preliminary results of its digital fabrication and assemblage process. The project follows the concept of integration between CAD, CAE and CAM systems, aiming at the automation of the processes that make mass customization of social housing in Brazil practicable.
\end{abstract}

Keywords: mass customization, social housing, parametric and algorithmic design, simulation, prediction, and evaluation, digital fabrication, building system

\section{INTRODUCTION}

Since the migration process from the countryside to urban areas during the industrial revolution in the 19th century, social housing became a pertinent issue in architecture (DUARTE, 2001). Currently, the housing production is still extensively based on the Fordist concept of mass production, which uses the standardization of components and the systematization of the manufacturing process. Although housing mass production using such methods has been important in different contexts throughout history, the consequent lack of personality of housing raises questions about its quality as it does not attempt the necessities of the residents (BENROS \& DUARTE, 2009).

From the second half of the 20th century, the growing needs of consumers for more personalized goods and services, in addition to advances in computation that arose during the same period, led to changes in production methods. Thus, the compu- tational revolution has affected a variety of industry fields, enabling high levels of product and service personalization to be achieved on an industrial scale. Using these new computational technologies, large industries were able to connect instantly with consumers and apply methods that are "sufficiently adaptable systems to produce a wide spectrum of different forms" (CELANI \& PUPO, 2008). One of these methods of production is known as mass customization, which is a process of manufacturing goods that allows the high level of product customization on an industrial scale.

Among the premises for mass customization, the automation of the design process, the manufacturing process, and the assembly process through tools that are economically available are predominant (PINE II, VICTOR, \& BOYNTON, 1993). The use of computational generative systems and digital manufacturing systems, capable of assisting the design and production automation process, can already be observed in 
certain areas of civil construction, that are looking for technological innovation. However, because of the characteristics of the final product, which includes its dimensional constraints, there are no economically available tools for the automation of the in situ buildings assemblage process. In South America, the situation worsens if taking into account that historically technological movements are usually delayed compared to those of developed countries in Europe and the United States (SPERLING, CELANI, HERRERA, \& SCHEEREN, 2015). Therefore, a consolidated alternative for the construction of digitally fabricated buildings is the creation of alternative systems based on the division of the building into smaller pieces that can be easily interlocked (GRIFFITH, WILLIAMS, KNIGHT, SASS, \& KAMATH, 2011). Nevertheless, some important criteria need to be considered for accepting such systems in developing countries, such as different formats of local cultural and social aspects embedded in the design of building systems, structural stability and safety, and the use of local materials (KNIGHT \& SASS, 2010).

This current work aims at demonstrating the systematization of methods that led to the proposal of a wood building system for mass customization in Brazil, which incorporates freely selected aspects of Brazilian popular architecture with an interlocking system for ease of assembly and is capable of being digitally manufactured with an available technology in the country. The application of the system in a CAD, CAE and CAM environment and the integration of those three platforms aim at the instantaneity of its production.

The study seeks to contribute with answers to two questions. First, how to make the assembly process of mass-customized housing feasible, in short and medium terms, without having an available technology to automate the large-scale assembly process. Second, how to integrate CAD, CAE and CAM processes to make housing mass customization possible.

\section{METHODS}

A major goal of the research was to develop a building system for mass customization of housing in Brazil. To accomplish this goal three steps were taken: [i] design conception of the building system; [ii] automation of the design and production processes; [iii] verification of assembly process viability. Each of the methods to accomplish these steps is explained in detail in the following sections.

\subsection{BUILDING SYSTEM DESIGN}

The system design was developed based on the design for a manufacturing and assembly method (DFMA) introduced by Boothroyd, Dewhurst, and Knight (2010) (as cited in Celani, 2014). In this design method, issues related to the manufacturing process are considered during the initial conception of the product in order to facilitate its fabrication and assembly. Thus, during the design process of the building system, different variables that influence the manufacturing and assembly process were taken into consideration. First, a digital manufacturing technology was determined with affordable market costs and availability in the region. Then, it was defined that manufacturing must be accomplished by using a two-axis CNC laser cutter machine or a two-axis CNC router. Second, it was necessary to define the material to be used taking into account the following criteria in order of relevance: (i) possibility of management with the chosen machinery; (ii) affordability; (iii) local availability; (iv) local cultural acceptance of the use of this material in civil construction. Based on these criteria, reforested wood sheets were selected for structural use, which can be specified in different formats depending on the project needs, such as glued-laminated timber, plywood or OSB. Third, the assembly of the building system must be a systematic process. It means that even while constructing a varied spectrum of forms, the worker will be able to assimilate the execution of the assembly by repetition. Finally, cultural formal and functional aspects of Brazilian popular architecture must be considered and embedded in the design of the building system. 
Figure 1

Building system creation process. (a) three-dimensional object is identified; (b) contours are made; (c) joints are introduced; (d) bidimensional objects are created.
For the first three variables, analyses of case studies of building systems that used the same technology and the same material were carried out . It was concluded that the best method to design the system was the two-axis lateral contouring of the artifact to be produced (SASS, 2007). In this methodology, the three-dimensional objects that form the building system are sliced in two perpendicular directions and from the lateral contours generated by slicing, bidimensional objects are created. After the creation of the bidimensional objects, male-female joints are embedded in them. These joints are used to connect the two-dimensional objects that form the three-dimensional objects and to connect one three-dimensional object to another (Figure 1). For the fourth variable, aspects of traditional building systems of Brazilian popular architecture were analyzed (VASCONSELLOS, 1979). These aspects were then chosen to be incorporated into the design of the system according to their relevance and the possibility of application with the predefined material.

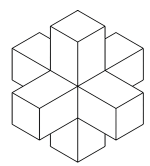

(a)

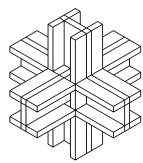

(b)

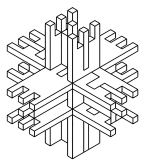

(c)

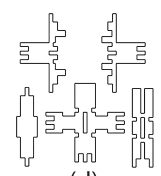

(d)

\subsection{AUTOMATION OF THE DESIGN AND PRODUCTION PROCESSES}

Design and production processes were automated by the interoperability between CAD, CAE and CAM platforms. A design automation of the building system was possible through its parametrization in a CAD environment. The 3D computational modeling platform Rhinoceros and the visual programming plugin Grasshopper were chosen. The computational simulation of structural performance was automated by the interoperability between CAD and CAE platforms, which was possible through a plugin developed in C(\#) language during this research.

\subsection{VERIFICATION OF ASSEMBLY VIABILITY}

For the verification of the assembly process a 1:1 scale prototype of selected parts of the system was fabricated. The digital fabrication of the connection samples was made in wood using a laser cutter. The 1:1 scale prototype made it possible to gather preliminary information about the ease of assembly and the climate influences on the integrity of the connections (metal connections or adherents were not used during this first stage).

\section{RESULTS}

\subsection{BUILDING SYSTEM}

The results of the work produced a wood building system capable of being manufactured by a CNC laser cutter or a CNC router. The generative system of the structure was conceived in two integrated scales. Firstly, bidimensional contours were fabricated from plywood sheets, then, these bidimensional parts were assembled to form tridimensional objects. The 2D and 3D parts are named "elements" and "components", respectively. Both elements and components were connected by a single male-female joint system. The system incorporated local cultural aspects of civil construction into its design.

The component definition is based on the configuration of Brazilian popular building systems and uses the same structural system. According to Vasconsellos (1979), Brazilian popular building systems can be divided into four different parts: structure, flooring, walls and ceiling. From several structural system classifications analyzed, an autonomous structural system was selected. This type of structure is composed of structural frameworks and structural trusses that are independent of the sealing parts that conform flooring, ceiling, and walls. Therefore, because of the type of structural system selected, the structural components are independent of the sealing components. On the other hand, the sealing components depend on the structural components.

The building system was classified by four different families named "bars", "connections", "trusses" 
Figure 2

3D geometric

conceptual model

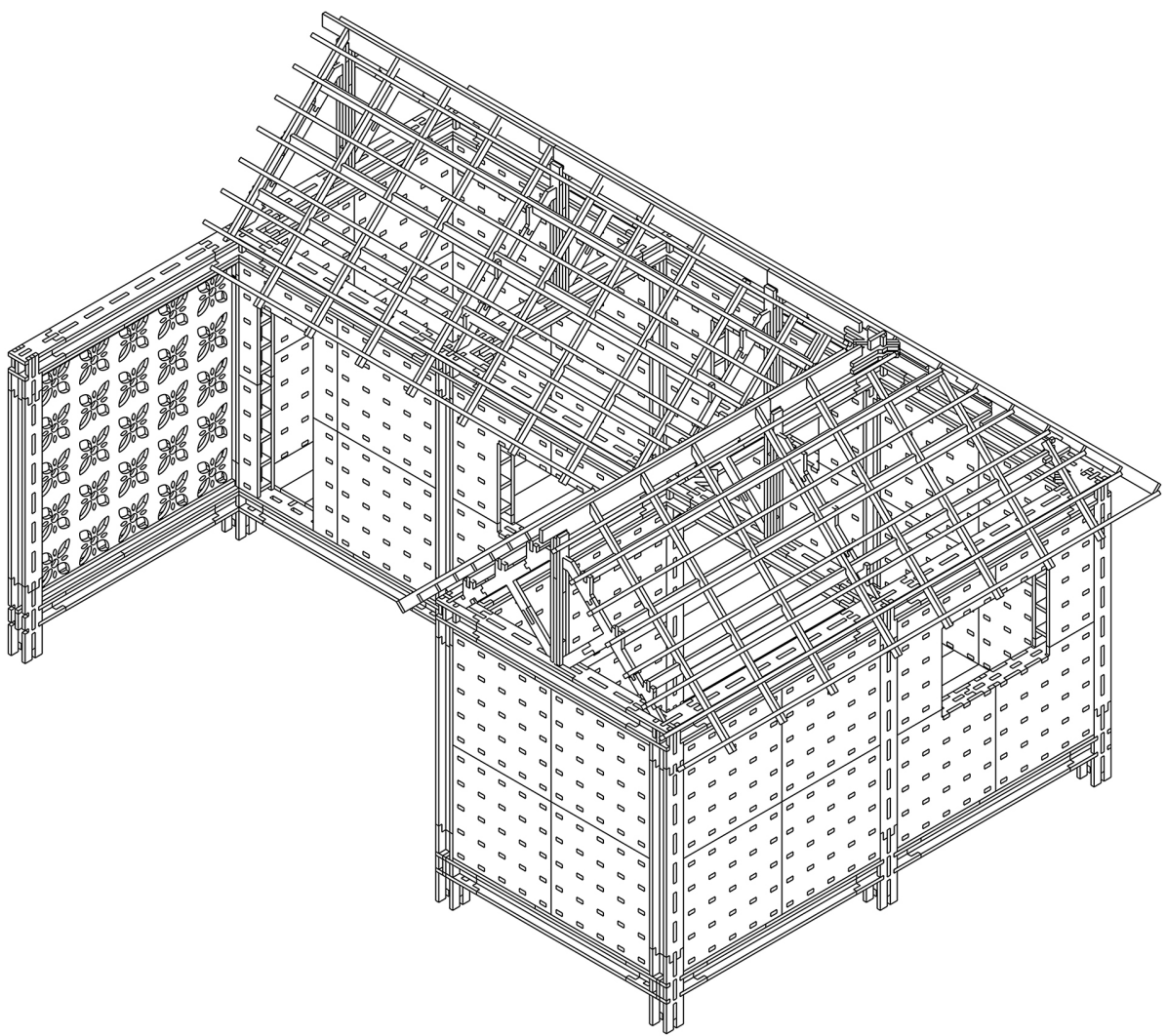

of the building

system 
Figure 3

Families of

components. a)

bars; b)

connections; $c$ )

trusses; d) sealing.

Figure 4

Comparison of building systems.

(a) connection

example; (b)

exploded view of

the connection; (c)

bars with

embedded joints. and "sealings". It must be emphasized that the manufacturing and assembly processes were taken as criteria by this classification. Components are objects that originate from the assembly of bidimensional elements. Thus, although by means of structural analysis a structural truss is considered as a group of bars and connections, according to the classification defined in this study, trusses are classified as a specific component family. Each of these families can be divided by types, sub-types and instances. For example, the connections within the structure are classified as types according to their higher, intermediate or lower position. The subtypes of connections are classified according to the number of exit axes.

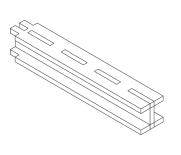

(a)

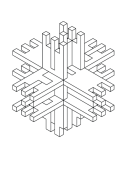

(b)

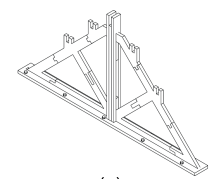

(c)

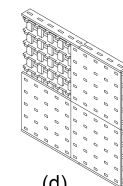

(d)
One of the goals of the proposed system is the ease of assembly, which is based on a single male-female joint system embedded in the elements, facilitating the connection between components. While in traditional systems analyzed the connections between parts vary according to their dimensions and the type of connection to be executed, in the developed system, independently of the type of connection, the action to be taken for assembly will always be the same.

Digitally fabricated wood building system
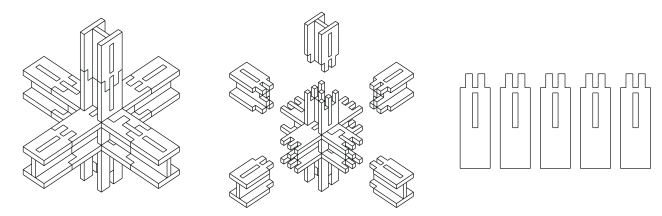

Traditional wood building system

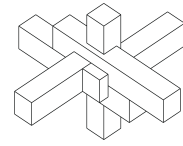

(a)

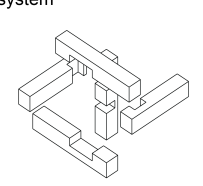

(b)

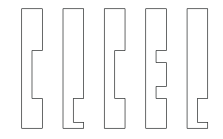

(c)

\subsection{PARAMETRIC MODEL}

The parametric model logic is based on the defined hierarchy classification of the proposed system design (Figure 5). The algorithm is powered by parameters of architectural design and constructive components. For each of the component families, there are specific parameters corresponding to their types and subtypes. Architectural design parameters define the point position used to construct reference lines to positioning the components. Then these lines work as references to define the coordinates for constructing 2D elements that together form 3D components. The user controls the architecture design parameters and some component parameters (free variables), while other component parameters are automatically regulated according to architecture design parameters (dependent variables). In this generative system, all element-related parameters are dependent variables.

\subsection{STRUCTURAL SIMULATION}

The parametric modeling of the components allowed approaches that predicted the structural performance based on the permissible stress design. The structural analysis is executed in an application based on finite elements to where the data is exported through a plugin developed for this research. Developed in C(\#) language for Grasshopper, this plugin allows that materials, profile shapes, loadings and support conditions can be defined in Rhinoceros (CAD environment). From this tool, all records are saved in a text file, following a conventional methodology in the structure analysis. Once the file is saved with the records, a program based on the Finite Element Method (CAE environment) is automatically executed, recognizing the text file as an input and proceeding to the structural analysis where internal force values and support reactions are obtained. An update of this code that allows the visualization of structural analysis results in the CAD environment is still being developed. At this stage, the automatically obtained requested forces on the bar elements feed spreadsheets where values of the internal forces and 


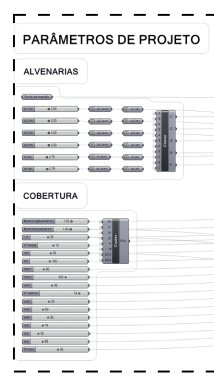

(a)



(b)

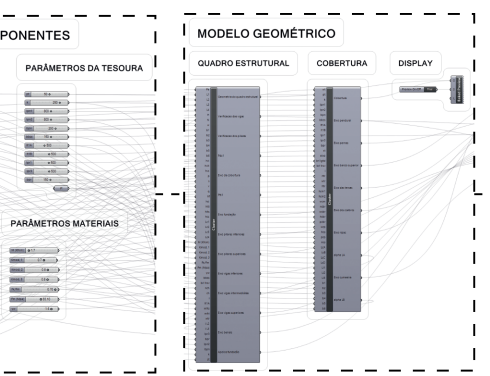

(c)

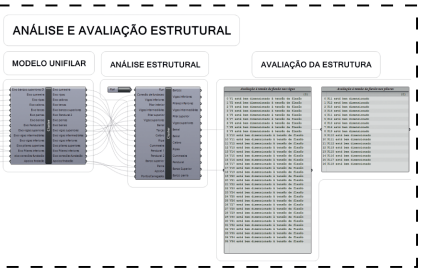

(d)


Figure 5

Building system

design solutions

generation

algorithm. (a)

architecture design

parameters; (b)

component

parameters; (c)

geometric model

(d) structural

simulation and

analysis.

Figure 6

Design variations

generated with the

algorithm

developed. 
Figure 7

Structural simulation and analysis of deformation and stress in the structural system realized with the integration of CAD and CAE platforms. the necessary resistance are calculated and used to adequate the design. After the dimensions are adjusted, a message of the type "the component is well (or badly) designed" is reproduced. Since the experimental campaign for the connections' resistance estimative is still found on a preliminary stage, simplified procedures for the system's design were adopted.
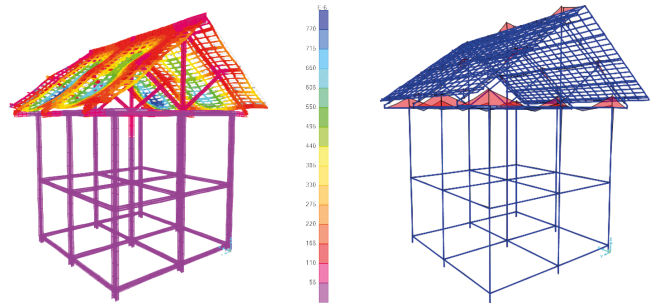

\subsection{PROTOTYPE}

At this stage of the study, focusing on the assimilation of manufacturing techniques and evaluation of assembly aspects of connections, three samples of components were selected to be manufactured and assembled using a $1500 \mathrm{~mm} \times 2000 \mathrm{~mm} \times 18 \mathrm{~mm}$ MDF sheet. The first component was a lower connection with four exit axes (Figure 8). This component was chosen because it is an example of a relatively complex connection and because there were doubts about the integrity of the joints in some of its elements. The other two components chosen are sections of bars for beams and columns, respectively. The prototypes were fabricated on a 1:1 scale with $100 \mathrm{~mm} \times 100 \mathrm{~mm}$ profile section and $18 \mathrm{~mm}$ thickness. The elements were fabricated using a Cutlite ${ }^{\circledR}$ CNC laser cutter machine with $1500 \mathrm{~mm} \times 2000 \mathrm{~mm}$ workspace. It is important to highlight that the same pieces could as well be properly fabricated using a $\mathrm{CNC}$ router machine. According to the machine operators, laser cutting is more precise and is capable of manufacturing the parts in less time. However, it produces unpleasant odors on the parts and darkens the edges, producing a poor visual appearance. This becomes a problem in cases where the architecture design takes into account the appearance of the struc- tural elements. The time needed to cut the pieces was 22 minutes.

\subsection{ASSEMBLY}

The assembly process of the components was based on male-female joints with $70 \mathrm{~mm}$ depth, $18 \mathrm{~mm}$, and $20 \mathrm{~mm}$ width, embedded in the elements. Two joints needed to be manually sanded for viability. The only necessary tools for the execution of the assembly were sandpaper and a rubber mallet. Also, the assembly of all three components could be made by just one person with no difficulty in less than 20 minutes. The connection between the components took less than 1 minute to be executed. The joints were connected using just pressure and, under preliminary evaluation, the integrity of connections was ensured (once two elements or two components were connected, it became difficult or impossible to separate them). How variations in the humidity of the environment affect the integrity of the connections is still under observation, but it has been noted that the joints have an higher integrity on days with higher relative humidity than on days with lower humidity.

\section{CONCLUSIONS}

The systematization proposed in this paper indicates the possibility of a method that allows the design of new building systems or the adaptation of existing ones that correspond local design specifications to facilitate the cultural and economic acceptance of mass customized and digitally fabricated housing. Future studies focus on how the design methodology can help to improve the definition of the variables to be considered in this systematization.

Results of this research suggest that the concepts of CAD, CAE, and CAM can be integrated to make mass customization of social housing possible through the initial development of a building system and pave the path for more detailed analysis and testing in the future.

Results on prototyping and assembly demonstrate that these processes worked. It is still necessary to verify the feasibility of sealing components. 




(a)

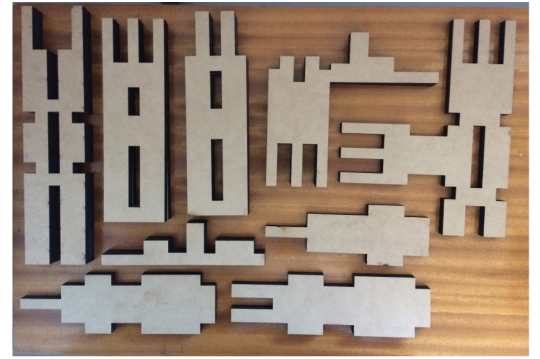

(b)

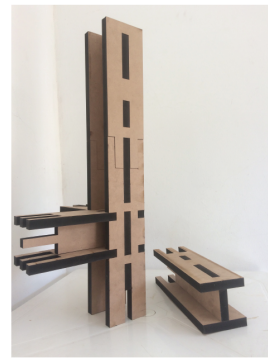

(c)
Since the assembly process is the same as those of the tested parts, expectations are positive. The integrity of joints presents a promising scenario for the use of the designed structure in an architecture and engineering project. However, a wide range of testing and studies still need to be carried out.

\section{REFERENCES}

BENROS, D and DUARTE, JP 2009, 'An integrated system for providing mass customized housing', Automation in Construction, 18, pp. 310-320

BOOTHROYD, G, DEWHURST, P and KNIGHT, W 2010, Product Design for Manufacture and Assembly, CRC Press

CELANI, MG 2014, 'Los siete mitos del detalle arquitectónico que están cambiando en la era digital', Arquitectura y cultura, 5(IISSN 0719-4374 ), pp. 48-60

CELANI, MG and Regiane, PUPO 2008, 'Prototipagem Rápida e Fabricação Digital para Arquitetura e Construção: Definições e Estado da Arte no Brasil', Cadernos de Pós-Graduação em Arquitetura e Urbanismo FAU Mackenzie, 8(ISSN 1809-4120), pp. 31-41

GRIFFITH, K, WILLIAMS, R, KNIGHT, T, Lawrence, SASS and KAMATH, A 2011, 'Cradle molding device: An automated CAD/CAM molding system for manufacturing composite materials as customizable assembly units for rural application', Automation in Construction, 21, pp. 114-120

PINE II, BJ, VICTOR, BI and BOYNTON, AC 1993, 'Making Mass Customization Work', Harvard Business Review, September-October 1993(93509), pp. 107-116

KNIGHT, T and Lawrence, SASS 2010, 'Looks count: Computing and constructing visually expressive mass customized housing', Artificial intelligence for engineering design analysis and manufacturing, 24(doi:10.1017/S0890060409990126), pp. 425-445

Lawrence, SASS 2007, 'Synthesis of design production with integrated digital fabrication', Atomation in Construction, 16, pp. 298-310

SPERLING, DM, CELANI, MG, HERRERA, PC and SCHEEREN, R 2015 'Fabricação digital na América do Sul: um mapeamento de linhas de ação a partir da arquitetura e urbanismo', Proceedings of Sigradi 2015, Santa Catarina, pp. 119-125

de VASCONSELLOS, S 1979, Arquitetura no Brasil: Sistemas Construtivos, Universidade Federal de Minas Gerais
Figure 8

a) manufacturing process of the parts;

b) fabricated bidimensional elements; c) assembled components. 